\begin{tabular}{|c|c|c|c|}
\hline Article Info & RESEARCH ARTICLE & ARAŞTIRMA MAKALESİ & \\
\hline Title of Article & \multicolumn{2}{|c|}{$\begin{array}{c}\text { A Greenway Proposal that Supporting } \\
\text { Urban Ecosystems: Case of Arhavi }\end{array}$} & \\
\hline $\begin{array}{l}\text { Corresponding } \\
\text { Author }\end{array}$ & \multicolumn{2}{|c|}{$\begin{array}{l}\text { Banu KARÁ } \mathbf{g A H} \\
\text { Artvin Çoruh Üniversitesi, Sanat ve Tasarım Fakültesi } \\
\text { banukarasah@ artvin.edu.tr }\end{array}$} & \\
\hline $\begin{array}{l}\text { Received Date } \\
\text { Accepted Date }\end{array}$ & \multicolumn{2}{|l|}{$\begin{array}{l}02.10 .2020 \\
29.12 .2020\end{array}$} & \\
\hline Author / Authors & Banu KARÁgAH & ORCID: 0000-0001-5079-5313 & \\
\hline How to Cite & \multicolumn{2}{|c|}{$\begin{array}{l}\text { KaraĢah, B. (2020). Kentsel Ekosistemleri Destekleyen Bir YeĢilyol Önerisi: Arhavi } \\
\text { Örneği. Kent Akademisi, Volume:13, Issue:4, 736-750. }\end{array}$} & $\begin{array}{l}\text { Kent Akademisi } \\
\text { Urban Academy }\end{array}$ \\
\hline
\end{tabular}

\title{
Kentsel Ekosistemleri Destekleyen Bir Yeşilyol Önerisi: Arhavi Örneği
}

\begin{abstract}
:
As a result of urbanization, qualified green-blue spaces are decreasing, and fragmentations occur in natural landscapes. Greenways are a strategic solution in creating sustainable and liveable cities and conserving fragmentation in landscapes. From this point on, in this study; it is aimed to planning a route that has natural and cultural resource values as a greenway that contribute to the green area system of the city, offer recreational activity areas to city residents, and protect historical-cultural values. An approximately $17 \mathrm{~km}$ waterfront corridor located in Arhavi district of Artvin city has chosen as the study area. Goal of the study is to support the existing urban ecosystem by offering different ecosystem services to both its users and the city because of planning a greenway by integrating a blue area with a green area. The study was carried out in 4 stages. In the first stage, field studies were carried out, SWOT analysis was made in the second stage, and in the third stage, corridors were defined and in the last stage, activities that could be performed in these corridors were determined and some suggestions were proposed. In addition, the ecosystem services that will be provided by the proposed greenway are stated in the study. Greenways are corridors that provide qualified green-blue spaces, provide recreation areas, protect landscape values, and contribute to the local economy through tourism. For this reason, it is vital to plan the greenways correctly.
\end{abstract}

KEYWORDS: Greenway, Urban green-blue spaces, SWOT analysis, Arhavi. 
ÖZ:

Kentleşme sonucu nitelikli yeşil-mavi alanlar azalmakta ve beraberinde doğal peyzajlarda parçalanmalar meydana gelmektedir. Yeşilyollar, sürdürülebilir ve yaşanabilir kentler oluşturmada ve peyzajlardaki parçalanmaları engellemede stratejik bir çözümdür. Bu noktadan hareketle bu çalışmada; doğal ve kültürel kaynak değerlerine sahip olan bir güzergâhın yeşilyol olarak planlanarak hem kentin yeşil alan sistemine katkıda bulunması, kent sakinlerine rekreasyonel açıdan aktivite alanı sunması hem de tarihi-kültürel değerlerin korunması amaçlanmıştır. Çalışma alanı olarak Artvin kentinin Arhavi ilçesinde yer alan yaklaşı 17 km'lik su kenarı koridoru seçilmiştir. Çalışmada, mavi bir alanın yeşil bir alanla bütünleştirilerek yeşilyol olarak planlanması sonucu hem kullanıcılarına hem de kente farklı ekosistem servisleri sunarak mevcut kent ekosistemini desteklemesi hedeflenmiştir. Çalışma 4 aşamalı olarak yürütülmüştür. Birinci aşamada arazi çalışmaları yapılmış, 2. aşamada GZFT analizi yapılmış ve 3. aşamada koridorlar tanımlanmış ve son aşamada ise bu koridorlarda gerçekleştirilebilecek etkinlikler belirlenerek önerilerde bulunulmuştur. Ayrıca çalışmada önerilen yeşilyol sayesinde sağlanacak ekosistem servisleri de belirtilmiştir. Yeşilyollar nitelikli yeşil-mavi alanlar kazandırarak rekreasyon alanları sağlayan, peyzaj değerlerini koruyan ve turizm sayesinde yerel ekonomiye katkı sunan koridorlardır. Bu nedenle yeşilyolların doğru bir şekilde planlanması önem arz etmektedir.

ANAHTAR KELĠMELER: Yeşilyol, Kentsel yeşil-mavi alanlar, GZFT analizi, Arhavi.

\section{"Kentsel Ekosistemleri Destekleyen Bir YeĢilyol Önerisi: Arhavi Örneği”"}

\section{GǴŔ் $\dot{\mathbf{g}}$}

Kentsel yeşil ve mavi alanlar kentsel ekosistemlerin önemli parçalarıdır. Ancak kentleşme peyzaj desenlerinde geçirimsiz yüzeylerin artması ve mavi-yeşil alanlarda azalma gibi köklü değişikliklere yol açmıştır (Estoque vd., 2017; Shiflett vd.,2017; Yu vd., 2019; Yu vd., 2020). Dünyada kentler, kronik trafik sıkışıklığı, aşırı enerji kullanımı ve şiddetli çevre kirliliğinin yanı sıra küresel iklim değişikliği ile karşı karşıya kalmıştır (Jang, 2015). Kentler, doğal ve oldukça değerli habitat ve türlerden bir araya gelmiş mozaik yapılardır (Acar \& Sarı, 2010). Maalesef hızlı kentleşme ve hızlı nüfus artışı sonucu doğal peyzajlarda parçalanmalar meydana gelmiştir. Bu sorunlara bir çözüm stratejisi olabilecek, sürdürülebilir ve yaşanabilir kentler/mekânlar oluşturmaya imkân tanıyacak eşsiz kentsel altyap1 unsurlarından biri de yeşilyollardır. Parklar, bahçeler, yeşil yollar, ormanlar, sulak alanlar, tarım alanları, yeşil çatılar, yeşil duvarlar ve diğer tüm kentsel yeşil alanları kapsayan yeşil kentsel altyapılar hem insanların hem de doğanın çıkarlarına hizmet eden kentsel sistemin önemli bir parçasıdır (Benedict ve McMahon; Chen vd., 2017).

Çok amaçlı planlanan ve özgün bir yeşil alan türü olan yeşilyollar üzerine çeşitli tanımlamalar yapılmıştır. Avrupa Yeşilyollar Birliği, yeşilyolları yalnızca motorsuz yolculuklar için ayrılmış hem çevreyi hem de etrafındaki yaşam kalitesini artıran entegre bir şekilde geliştirilen iletişim yolları olarak ifade etmiştir (EGWA, 2002; Senes vd., 2017). Corning vd. (2012) yeşil yolları, genellikle kentsel nüfus merkezlerine daha yakın olan, genellikle asfalt kaplı/döşenmiş, kaldırımlardan veya yürüyüş yollarından daha geniş ve çeşitli demografik yapıya sahip bireyler için daha erişilebilir olan çok amaçlı yollar olarak tanımlamaktadır. (Weber vd., 2017). Yeşilyollar, habitatların parçalanmasını önlemek ve doğal ekolojik sistemlerin bütünlüğünü korumak için farklı ekolojik alanları birbirine bağlayan çok işlevli doğrusal yeşil alanlardır (Little, 1995; Liu vd., 2018). Ngo ve ark. (2018), "bisiklet olanakları ve sokak manzaralarının iyileştirmelerinin bağdaştırılmasıyla düzenlenmiş ve trafiği sakinleştirilmiş yollar" olarak tanımlanan "yeni kentsel yeşilyollar" terimini önermiştir (Liu vd., 2020). Yeşilyollar; birden fazla hedefe sahip bir kavram olarak ve insanlara parkurlar boyunca yenilenme veya gidip gelirken arzu edilen estetik nitelikler sunarken doğal işlevleri yerine getiren açı alan koridorları olarak tanımlanabilir (Shafer vd., 2000). Yeşil yollar bu nedenle hem doğal kaynakların korunmasında hem de sağlıklı bir yaşam tarzının teşvik edilmesinde önem arz etmektedir (Paneerchelvam vd., 2020). Yeşilyollar; sadece bir konumdan diğerine gitmek için bir yol olmaktan çok, etkinlikler ve deneyimler için ortamlardır (Taylor, 2015; Rovelli vd., 2020).

Doğrusal yapıları nedeniyle yeşilyollar, kentsel habitatları ve bunlarla ilişkili biyolojik çeşitliliği birbirine bağlamakta (Ahern, 2013; Bryant, 2006) ve kalabalık şehirlerde insanlar ve doğa arasında olumlu etkileşimler için firsatlar yaratmaktadır (Gobster, 1995; Chon ve Shafer, 2009). Yeşilyollar fiziksel sağlık ve egzersize katkıda bulunarak (Fitzhugh vd., 2010; Dallat vd., 2014;) ve kentsel parkları ve mahalleleri birbirine bağlayan aktiviteyi teşvik eden ulaşım firsatları sağlayarak (Shafer vd., 2000) bireylerin yaşam kalitesini arttırmaktadır (Keith vd., 2018). İş, alışveriş veya okul gibi günlük etkinliklere katılmak üzere seyahat edenlere ulaşım için ana yol görevi görmektedir (Rovelli 
vd., 2020). Yeşil yollar aynı zamanda bir ekolojik hizmet biçimidir (Paneerchelvam vd., 2020). Yeşil yollar, toprağ sağlamlaştırma, taşkın kontrolü sağlama, suyu temizleme ve havayı arıtmada yardımcıdır (Anthony, 2006; Qin, 2012; Liu vd., 2018).

Genel olarak, beş temel yeşil yol türü vardır: (1) kentsel nehir kenarı yeşilyolları, (2) yollar ve patikalar içeren rekreasyon amaçlı yeşilyollar, (3) ekolojik olarak önemli koridorlar, (4) Manzara ve tarihi yollar ve (5) kapsamlı yeşilyol sistemleri veya ağlar (Little, 1990; Paneerchelvam vd., 2020).

Dünyada ve ülkemizde yeşilyollar ihtiyaç duyulan ve gündemde olan bir konudur. Literatürde konuya ilişkin güncel çalışmalar incelendiğinde; yurt dışında yapılan çalışmaların daha çok mevcut yeşilyollar üzerine olduğu ve kullanıcı tercihleri, kullanım sıklığını belirlemek amacıyla anket çalışmaları yapıldığı (Chen vd., 2017; Keith, 2018; Palardy vd., 2018), yine yeşilyollarda mekânsal veri analizini gerçekleştirmek için ise CBS (Coğrafi Bilgi Sistemi)'den faydalanıldığı (Sims-Golud vd., 2019; Rovelli vd., 2020) görülmüştür. Ülkemizde yapılan çalışmaların ise mevcut yollar üzerine yapılan çalışmalar kısıtlı olsa da daha çok optimum yeşilyol güzergahları belirlemek ve mevcut yeşil alanları bağlayan öneri yeşilyollar üzerine olduğu tespit edilmiştir. Örneğin Akpınar (2016) çalışmasında Koşuyolu kentsel yeşilyolunda (Aydın) kullanıcıların tercihlerini belirlemek ve yeşilyolun kullanımını etkileyen faktörleri belirlemek amacıyla anket çalışmasını kullanmıştır. Kurt (2013) ve Gömeli (2018) ise çok işlevli bir yeşilyol sistemi kurgulamak amacıyla anket çalışmaları yürüterek elde edilen veriler 1şığında optimum yeşilyol güzergahları belirlemişlerdir. Zengin vd., (2019) ise çalışmalarında arazi çalışması ve sorun ve imkanları belirledikleri GZFT analizini yapıp odak noktaları belirlemişler ve odak noktalarındaki doğal izleri takip edip potansiyel yeşilyolu belirleyip bu yeşilyola ilişkin önerilerde bulunmuşlardır.

Bu çalışmada; doğal ve kültürel kaynak değerlerine sahip olan kentsel bir alanı kırsal bir alana bağlayan güzergâhın yeşilyol olarak planlanarak hem kentin yeşil alan sistemine katkıda bulunması, kent sakinlerine rekreasyonel açıdan aktivite alanı sunması hem de kültürel değerlerin korunması amaçlanmıştır.

\section{MATERYAL VE YÖNTEM:}

Çalışmanın ana materyalini Türkiye'nin kuzeydoğusunda yer alan Artvin kentinin Arhavi ilçesinde yer alan su kenarı koridoru oluşturmaktadır. Çalışma alanının başlangıç noktasını Mençuna Şelalesi, bunu takiben Arhavi Deresi ve Orçi Çayı üzerinde kurulan Çiftekemer Köprüler ve bitiş noktasını ise Kapisre deresinin denizle buluştuğu nokta oluşturmaktadır. Çalışma alanı güzergâhı yaklaşı 17 km'dir. Bu güzergâh üzerinde Sanayi Sitesi, Artvin Çoruh Üniversitesi Arhavi Yerleşkesi, yerleşim alanları ve yeme-içme alanları da yer almaktadır (Şekil 1).
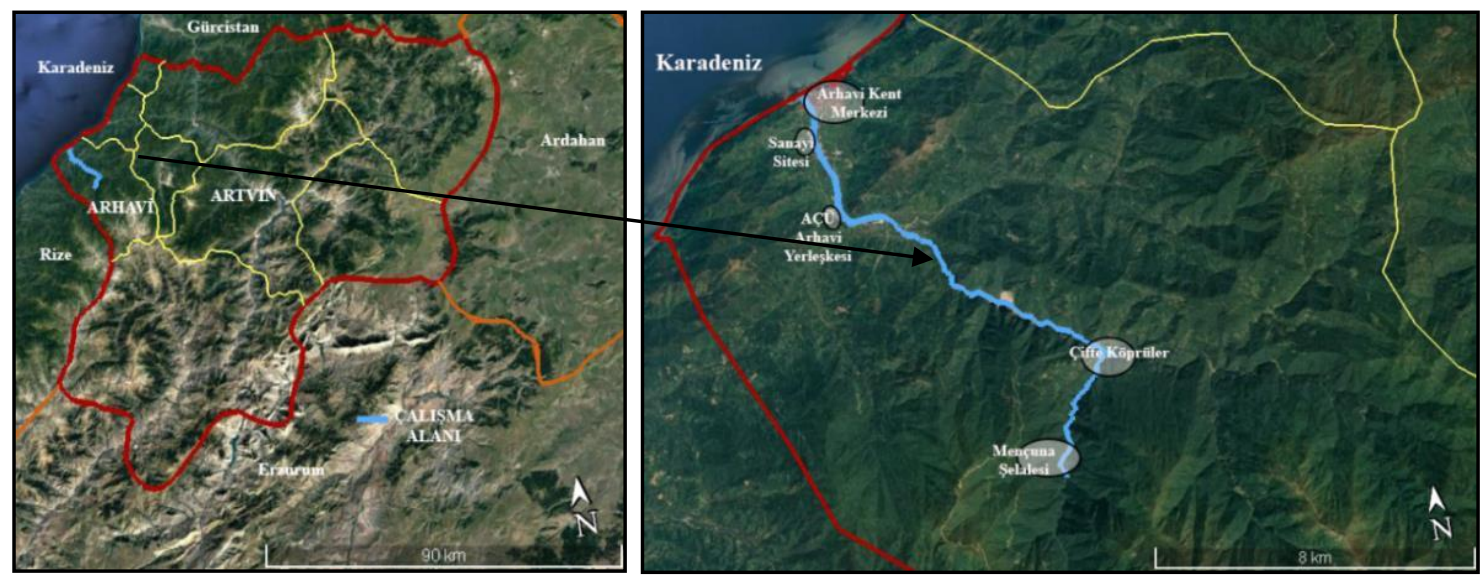

gekil 1. Çalışma alanı

Yeşil Artvin olarak isimlendirilen Artvin kentinin önemli bir parçası olan ve çalışmanın da yürütüldüğü Arhavi kentinde maalesef pasif yeşil alanlar yoğunluktadır. Kentte aktif yeşil alan kapsamında değerlendiren tek alan kent merkezinde yer alan kent parkıdır. Çalışma alanı güzergâhı; kent ile kırsal yerleşim bölgeleri ve kentin turizm değerleri arasında ulaşım imkânı sağlayan bir koridor niteliğindedir. Çalışma alanı olarak bu güzergâhın seçilmesinin 
nedeni; bu güzergâhın barındırdığı doğal, kültürel ve turizm değerlerinin koruma kullanma dengesi çerçevesinde değerlendirilmesinin yeşilyol yaklaşımı ile mümkün kılınacağı varsayımıdır ve çalışma alanında en az müdahale ile kente aktif yeşil alan kazandırılarak ve mevcut yeşil alanla da entegrasyonu sağlanarak kentin ekosistemine katkı sağlanabileceğinin düşünülmesidir.

Çalışma birbirini izleyen 4 aşamada gerçekleştirilmiştir (Şekil 2).

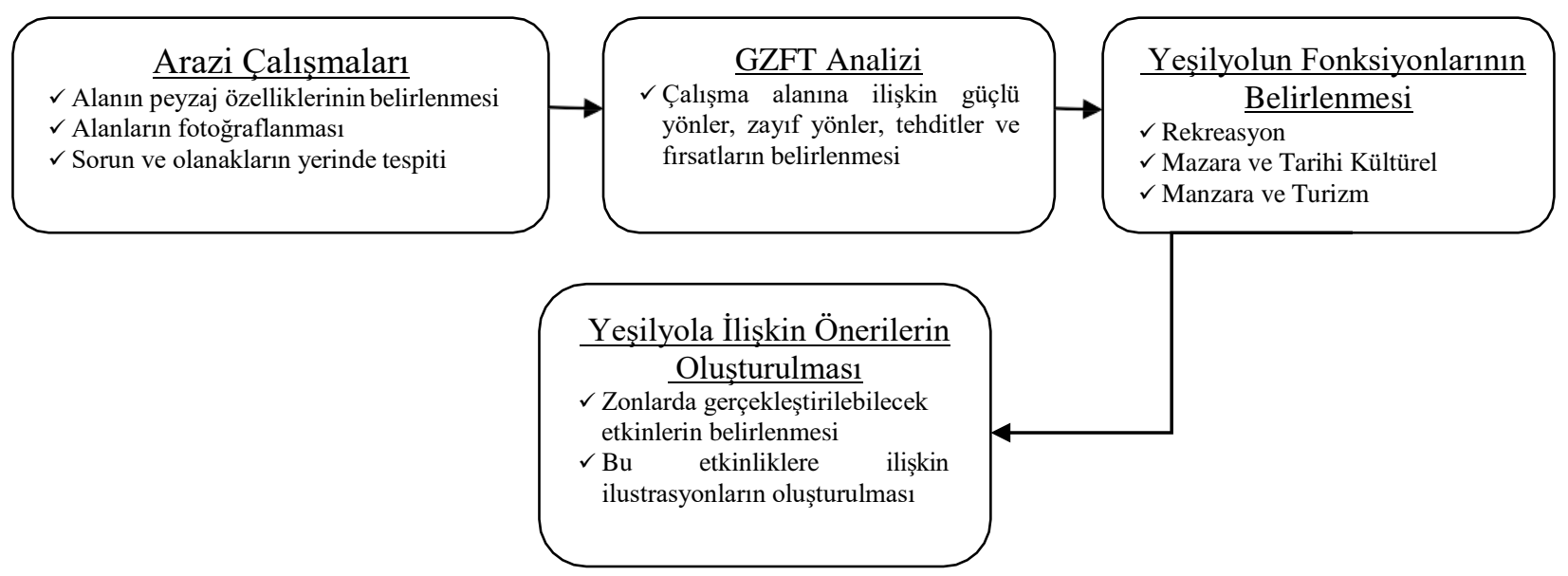

gekil 2. Yöntem akış şeması

İlk aşamada arazi çalışmaları yapılmış ve çalışma alanı üzerinde fotoğraflar çekilmiştir. Arazi çalışmaları, alanın peyzaj özelliklerinin belirlenmesi, çalışma alanındaki sorunların ve olanakların yerinde tespit edilmesi ve fotoğraflanması amacıyla gerçekleştirilmiştir. Çalışma alanına ait fotoğraflar 2020 yılı ağustos ayında Nikon D 7200 fotoğraf makinesiyle 13:00-15:00 saatleri arasında çekilmiştir. Çalışmada alanının peyzaj özellikleri; arazi kullanım deseni, alanın yapay ögeleri ve arazi morfolojisi başlıkları altında irdelenmiştir.

Büyüközkan vd., (2020) GZFT analizinin bir stratejik duruma ilişkin güçlü ve zayıf yönlerin belirlenmesi ve firsat ve tehditlerin tanımlanmasında kullanılan stratejik bir yaklaşım olduğunu ifade etmişlerdir. Buradan hareketle çalışmanın ikinci aşamasında böyle bir stratejik yaklaşım benimsenerek çalışma alanının güçlü ve zayıf yönleri, firsatları ve tehditleri belirlenmeye çalışılmıştır. GZFT analiziyle elde edilecek veriler doğrultusunda benimsenecek yeşilyol yaklaşımıyla güçlü yönlerin daha kuvvetlendirileceği, zayıf yönlerin alınacak tedbirlerle güçlü yöne çevrileceği, tehditlerin minimize edileceği ve firsatların değerlendirilebileceği varsayılmıştır.

\section{BULGULAR:}

\subsection{Arazi ÇalıĢmalarından Elde Edilen Bulgular:}

Çalışmanın ilk aşaması olan arazi çalışmasında, alana ilişkin doğal ve kültürel değerler, peyzaj özellikleri belirlenmiş ve fotoğraflanmış, çalışmanın ikinci aşamasını desteklemek amacıyla sorun ve olanaklar yerinde tespit edilmiştir. Çalışma alanı sahip olduğu korunmaya değer kaynak değerleri (topoğrafya-bitki birlikleri, tarihi köprüleri, su yüzeyi), mevsimsel açıdan sunduğu farklı vistaları ile önemli bir potansiyel sunmaktadır. Çalışmada alanı peyzaj özellikleri açısından ele alındığında; yaklaşık 17 km'lik güzergâhta, kullanıcılar geniş yapraklı ağaçlı alanları ve bunların mevsimsel değişimini, ibreli ağaçlı alanları, bunların karışık bir arada olduğu alanları, köy yerleşim alanlarını ve tarım alanlarını gözlemleme fırsatına sahiptir. Aynı zamanda güzergâh arazi morfolojisi açısından sunduğu dere, vadi ve dağ birlikteliği ile de özgün bir peyzaj yapısına sahiptir. Güzergâhın yapay özelliklerinde yer alan enerji nakil hatları, taşa ocakları ve hidroelektrik santraller negatif olarak değerlendirilebilecekken, güzergâh üzerinde görülebilecek olan Çiftekemer köprüler ve mevcut tesisler alana pozitif yönde katkı sağlayabilecek yapay peyzaj özellikleridir (Şekil 3). 

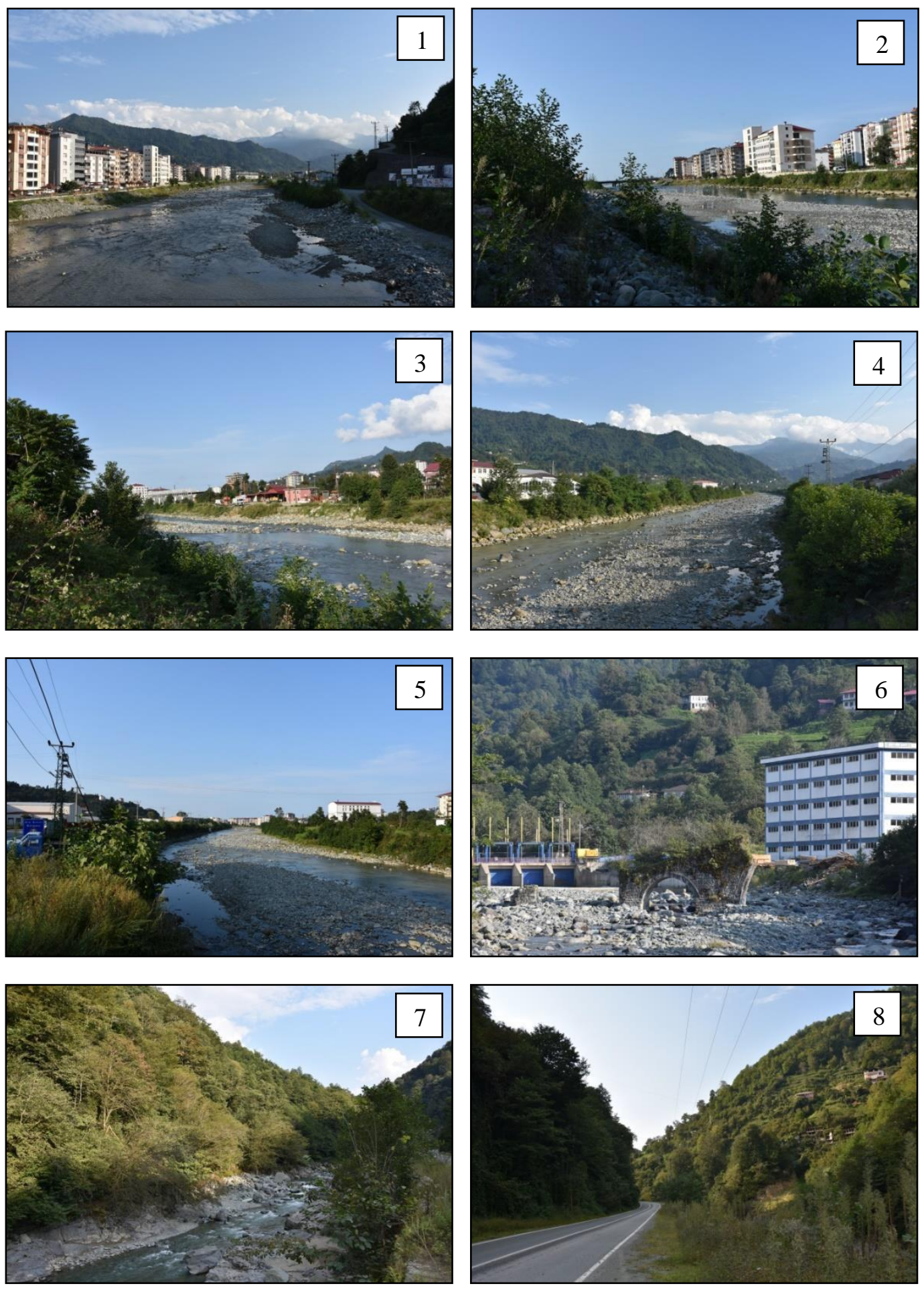

gekil 3. Çalışma alanından görüntüler (Orjinal, 2020) (rekreasyon koridoru olarak değerlendirilmesi düşünülen alana ait görseller (1-8), manzara ve tarihi-kültürel koridor olarak değerlendirilmesi düşünülen alana ait görseller (9-13), manzara ve turizm koridoru olarak değerlendirilmesi düşünülen alana ait görseller (14-20)) 
gekil 3 devam (Orijinal, 2020)
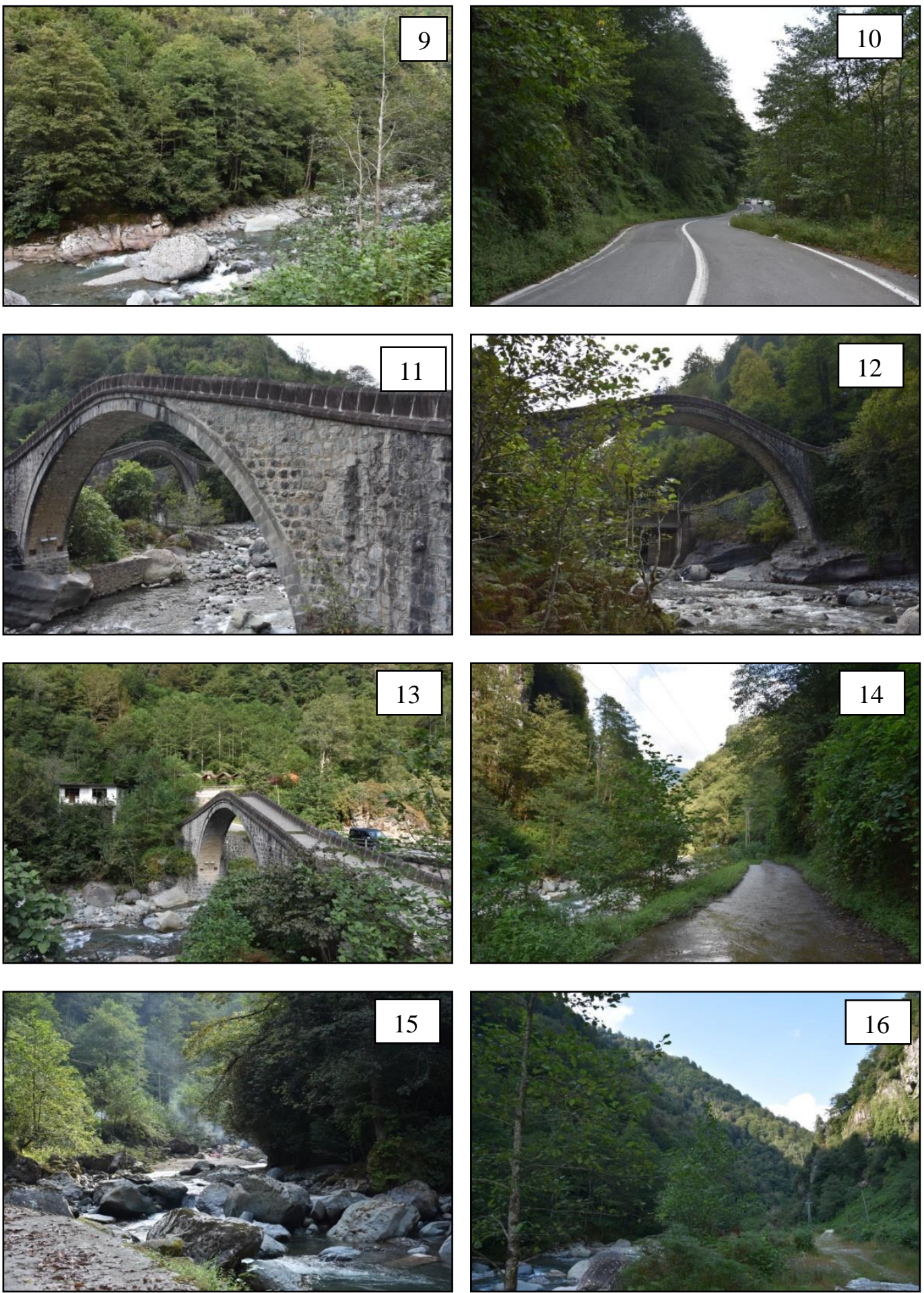

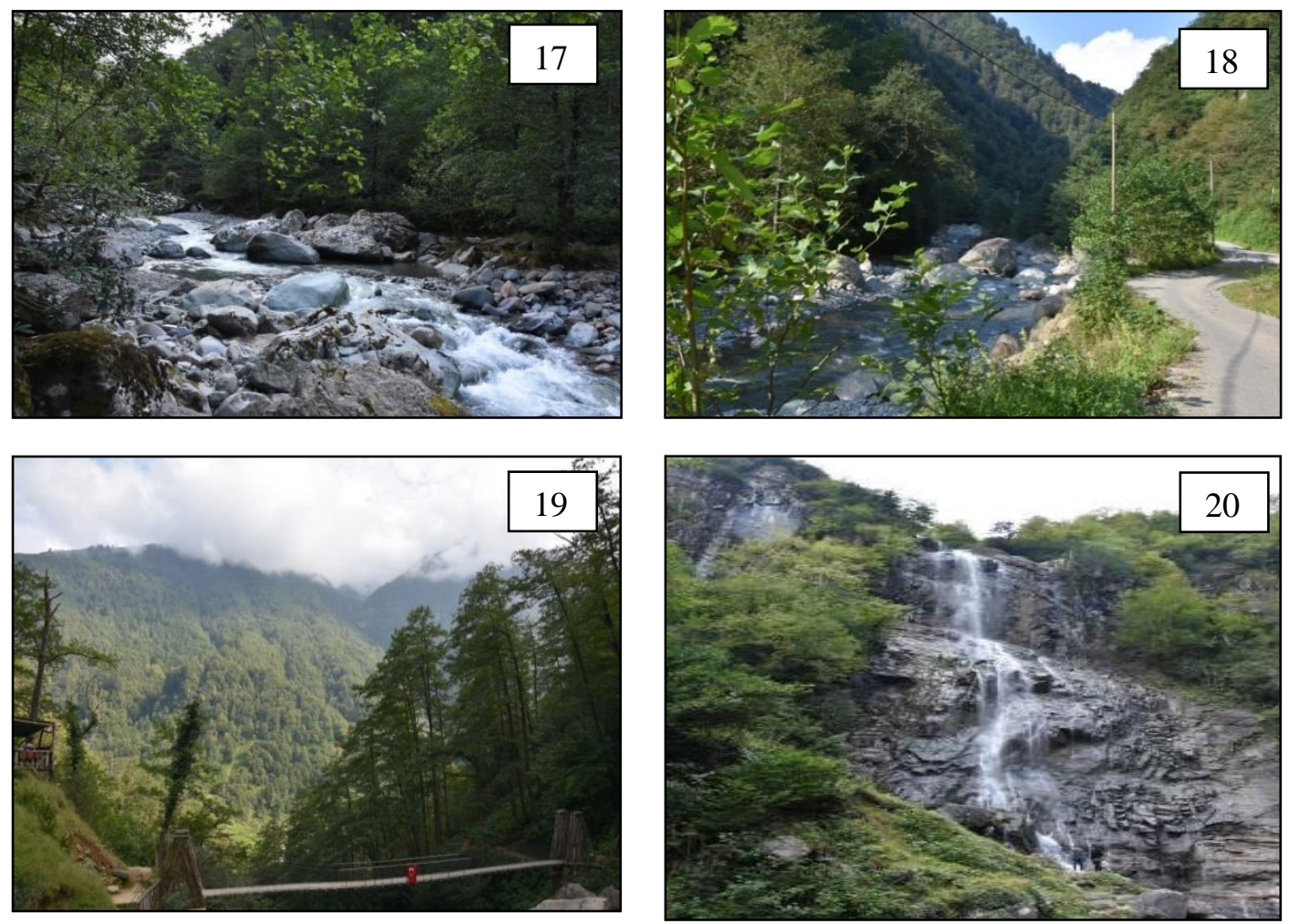

\subsection{GZFT Analizinden Elde Edilen Bulgular}

Çalışmanın ikinci aşamasında arazi çalışmasında yapılan gözlemler ve elde edilen veriler ışığında GZFT analizi yapılmıştır. Çalışma alanının manzara değeri, temiz havası, güzergâhta su varlığı, alanının doğal, kültürel ve tarihi turizm değerlerinin varlığı güçlü yönler olarak tespit edilirken güzergâh üzerinde HES varlığı, dere 1slah çalışmalarının devam etmesi ve aktif yeşil alanların olmaması gibi faktörler zayıf yönler olarak belirlenmiştir. Ayrıca çalışma alanında doğal ekosistemi tehdit eden istilacı türlerin varlığı (örn. Ailanthus altissima) ve dere ıslah çalışmalarının tamamlanmamasından ötürü su taşkınları olma olasılığı tehditler olarak tespit edilmiştir. Dünyada ve ülkemizde yeşilyollara olan ilginin artması, güzergâhta Mençuna Şelalesi'nin ve tarihi Çiftekemer Köprüler 'in varlığı ve güzergâhın rekreasyonel aktivitelere olanak tanıması gibi firsatları çalışma alanının sunduğu belirlenmiştir (Tablo 1). Fabos ve Ryan (2006) yeşilyolların; doğa koruma, maksimum rekreasyon ve turizm olanakları sağlamak ve tarihi ve kültürel kalıntıları korumak ve yenilemek olmak üzere 3 ana amacı olduğunu belirtmiş̧tir. Bu noktada yapılan arazi çalışmaları ve analiz verileri ışığında çalışma alanının barındırdığı değerleriyle bu üç amacı karşılayacak potansiyele sahip bir yeşilyol olarak değerlendirmesinin mümkün olduğu görülmüştür.

\subsection{Elde Edilen Veriler IG̣ığında Koridorların Tanımlanması}

GZFT analizi sonucunda elde edilen veriler ışı̆ğında güzergâhta zonlamalar yapılıış ve koridorlar tanımlanmıştır. Bu tanımlamada Kurt (2013) tarafından ifade edilen yeşilyolların fonksiyonları açıklamalarından faydalanılmışıı. Kurt (2013) alanın tarihi-kültürel ve anlamsal değerlerinin korunması, yaşatılması ve tanıtılmasına imkân veren bir koridor niteliğinde olmasını tarihi-külttürel değerleri koruyan koridor olarak, alanda yürüyüş yapma, bisiklet sürme, paten kayma, fotoğraf çekme, inceleme ve gözlemlerde bulunma, piknik yapma, kamp yapma, balık tutma, sportif etkinliklerde bulunma gibi rekreatif etkinliklere imkân veren bir koridor niteliğinde olmasını rekreasyon koridoru 
olarak, alandaki tarihi-kültürel unsurların tanıtılmasına, alanın cazipliğinin artmasına ve dört mevsim boyunca kullanılmasına imkân veren bir koridor niteliğinde olmasını turizm koridoru olarak ve alanda yol boyunca var olan tarihi-kültürel ve anlamsal değerlerin seyrine ve manzara fotoğrafçıllğına imkân veren bir koridor niteliğinde olması manzara koridoru olarak tanımlamıştır.

Tablo 1. Calıșma güzergahına ilișkin GZFT analizi

\begin{tabular}{|c|c|}
\hline Güçlü Yönler & Zayıf Yönler \\
\hline Suyun varlığ1 & Güvenlik \\
\hline Suya dayalı rekreasyonel aktivitelere imkân tanıması & Kentteki yapılaşmanın bu alana doğru kayması \\
\hline Karayolu ulaşımının olması & $\begin{array}{l}\text { Pasif yeşil alanların yoğun olmasına karşın aktif yeşil } \\
\text { alanların olmaması }\end{array}$ \\
\hline Yöreye özgü yemeklerin olması & Su üzerinde HES’lerin varlığı \\
\hline Temiz hava & Dere ıslahı çalışmalarının devam etmesi \\
\hline Yeme-içme alanlarının olması & Tehditler \\
\hline Manzara değeri & Doğal ekosistemi tehdit eden istilacı türlerin varlığ1 \\
\hline Doğa- temelli turizm değerlerini barındırması & $\begin{array}{l}\text { Dere ıslahının tamamlanmamasından dolayı alanda su } \\
\text { taşkını olasılığ } 1\end{array}$ \\
\hline Doğal bitki örtüsü & Toprak kayması ve heyelan riski \\
\hline Kültürel turizm değerlerini barındırması & Ağır tonajlı araçlar tarafindan yoğun kullanılması \\
\hline Yöre insanının turizme bakış açısının olumlu olması & $\begin{array}{l}\text { Dönemsel turizm aktiviteleri dolasıyla meydana gelen } \\
\text { çevre kirliliği }\end{array}$ \\
\hline \multicolumn{2}{|r|}{ Firsatlar } \\
\hline Mençuna Şelalesi’nin varlığı & Doğa-temelli turizm aktivitelerine imkân tanıması \\
\hline Tarihi Ciftekemer Köprüler 'in varlı̆̆g & Kent sakinlerinin artan yeșil alan talebi \\
\hline Rekreasyonel aktivitelere olanak tanıması & Koridor boyunca doğal peyzaj örüntülerinin varlığı \\
\hline $\begin{array}{l}\text { Dünyada ve ülkemizde yeşilyollara olan ilginin } \\
\text { artması }\end{array}$ & Yerel ekonomiye destek sağlayacak olması \\
\hline
\end{tabular}

Çalışmada bu tanımlamalardan faydalanılarak 3 farklı koridor tanımlanmıştır. Mençuna Şelalesi'nden Çiftekemer Köprülere kadar olan kısım (Çiftekemer Köprüler de dahil) turizm ve manzara koridoru olarak (harita üzerinde sarı renkle ifade edilmiş), Çiftekemer Köprüler ve yakın çevresi tarihi-kültürel değerleri koruyan bir koridor ve manzara koridoru olarak (harita üzerinde mor renkle ifade edilmiş)ve bu koridorun bittiği noktadan çalışma alanının sonuna kadar olan kısımda rekreasyon koridoru (harita üzerinde turuncu renkle ifade edilmiş) olarak sınıflandırılmıştır (Şekil $4)$.

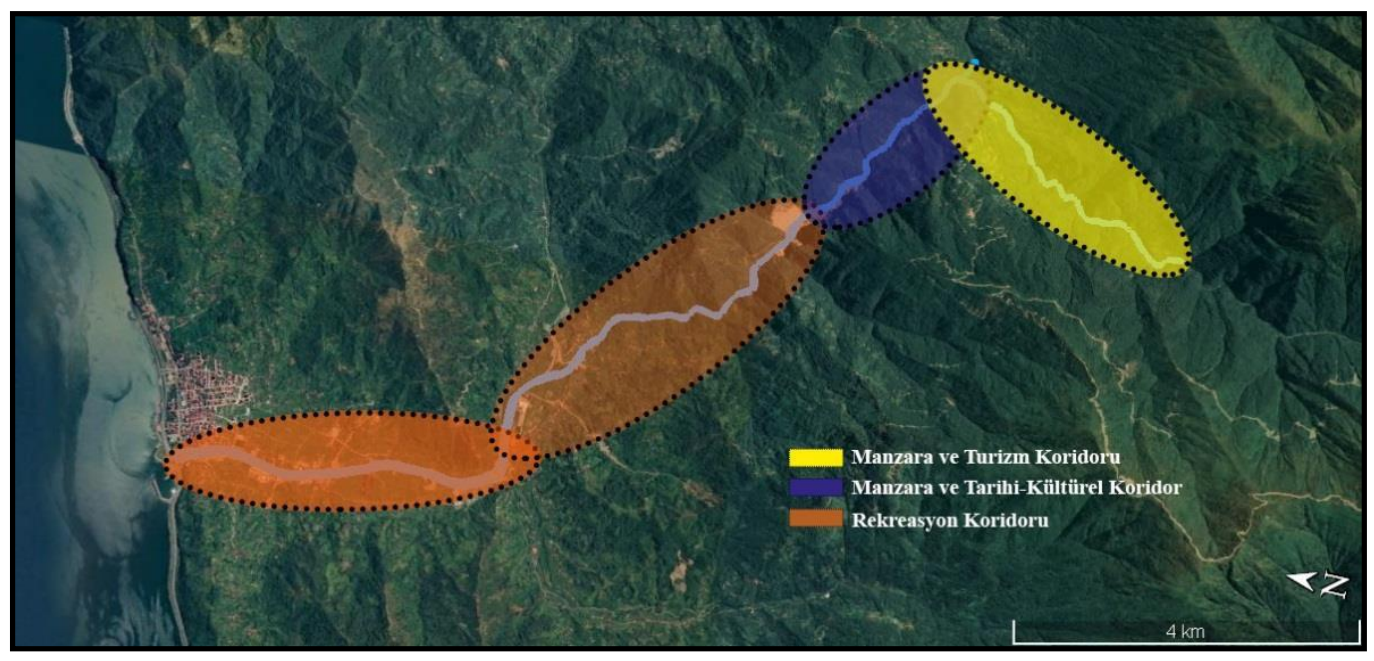

gekil 4. Önerilen yeşilyol koridoruna ilişkin belirlenen fonksiyonlar 
Manzara ve turizm koridoru olarak koridorun belirlenmesindeki temel etkenler; yeşil ve mavi alanların (dağ silüetleri dere, şelale) birlikteliğinin sunduğu manzara değerinin yüksek olması ve Mençuna Şelalesi'nin ve Çiftekemer Köprülerin turizm açısından büyük bir potansiyele sahip olmasıdır.

Koridorun; manzara ve tarihi-kültürel değerleri koruyan bir koridor olarak belirlenmesindeki etkenler, 18 yy. da yapıldığı tahmin edilen Çiftekemer Köprülerin bu koridorda yer alması ve yine yeşil alan-su varlığının oluşturduğu manzara değerinin yüksek olmasıdır.

Son olarak rekreasyon koridoru olarak belirlenen koridorun etkenleri; öncelikle kent merkezine yakın olmasıdır. Kent merkezinde aktif yeşil alan olarak kullanılan sadece bir adet park vardır. Sonrasında bu koridorun içerisinde sanayi sitesi, liseler ve üniversite yerleşkesi yer almaktadır. Bu alanlardaki kullanıcıların hem daha kısa sürede hem de güvenli bir şekilde koridor içerisinde önerilen aktivite alanlarına ulaşması hedeflenmiştir. Rekreasyon koridoru 2 bölüme ayrılmıştır. Birinci kısım kente yakın olan kısım diğeri ise birinci kısmı tarihi-kültürel koridorla bağlayan kısımdır. Birinci kısım kente yakın olmasından ötürü bu kısımda daha çok aktivite çeşitliliğinin kurgulanması planlanmaktadır.

\section{SONUÇ ve ÖNERǴLER:}

Kentsel ekosistemleri destekleyen yeşil-mavi alanlar, yanlış alan kullanımları sonucu her geçen gün azalmaktadır. Oysaki bu alanların arttırılarak doğadan kopan insanların yeniden doğayla bütünleşmesinin sağlanması ve insanların bu alanlardan daha verimli bir şekilde faydalanarak refahlarının arttırılması ve böylece daha yaşanılabilir kentlerin oluşturulması büyük önem arz etmektedir. Bu noktada yeşilyollar barındırdıkları özellikleri dolasıyla sürdürülebilir peyzajların planlanması ve korunmasında stratejik bir araç olarak rol almaktadır.

Çalışmada arazi çalışmaları yapılmış ve peyzaj özellikleri ortaya konulmuştur. Ayrıca GZFT analizi yapılarak çalışma alanındaki güçlü ve zayıf yönleri, tehditler ve firsatlarda belirlenmeye çalışılımıştır. Bu noktada çalışma alanının güçlü yönlerinin çok olduğu ve birçok firsat sunduğu tespit edilmiştir. Elde edilen veriler ve çalışmanın hedefi doğrultusunda güzergah üzerinde rekreasyon koridoru, manzara ve tarihi-kültürel değerleri koruyan bir koridor ve manzara-turizm koridoru olmak üzere 3 farklı koridor şeklinde değerlendirilmesi düşünülmüştür. Daha sonrasında bu koridorlarda gerçekleştirilebilecek aktiviteler belirlenmiştir (Tablo 2).

Tablo 2. Koridorlarda gerçekleştirilebilecek aktiviteler

\begin{tabular}{|c|c|c|c|}
\hline & Rekreasyon Koridoru & $\begin{array}{c}\text { Manzara ve Tarihi-Kültürel } \\
\text { Değerleri Koruyan Bir Koridor }\end{array}$ & $\begin{array}{l}\text { Manzara ve Turizm } \\
\text { Koridoru }\end{array}$ \\
\hline 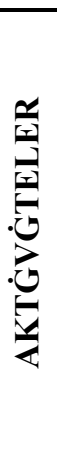 & $\begin{array}{l}\text { Yürüme } \\
\text { Oturma-dinlenme } \\
\text { Bisiklet sürme } \\
\text { Paten kayma } \\
\text { Fotoğraf çekme } \\
\text { Yeme-içme } \\
\text { Seyir-gözlem } \\
\text { Oyun oynama (yer } \\
\text { santranc1, dev puzzle vb) } \\
\text { Gösteri (müzik,dans) } \\
\text { Olta balıkç1lı̆g }\end{array}$ & $\begin{array}{l}\text { Manzara seyri } \\
\text { Oturma-dinlenme } \\
\text { Yeme-içme } \\
\text { Bisiklet sürme } \\
\text { Çay toplama } \\
\text { Islık dili ögrenme } \\
\text { Fotoğraf çekme } \\
\text { Eğlence (varangela ile su üzerinde } \\
\text { gezme) }\end{array}$ & $\begin{array}{l}\text { Yürüme } \\
\text { Trekking } \\
\text { Yüzme } \\
\text { Kamp } \\
\text { Oryantiring } \\
\text { Meditasyon } \\
\text { Piknik } \\
\text { Fotoğraf çekme } \\
\text { Doğa eğitimi } \\
\text { Manzara seyri }\end{array}$ \\
\hline
\end{tabular}

Elde edilen tüm veriler ışında çalışma alanına ilişkin tasarım önerilerinde bulunulmuş ve bu önerilere ilişkin illüstrasyonlar oluşturulmuştur.

Tüm güzergâh boyunca araç yoluna ve dere kenarındaki alanlarına en az müdahale edilmelidir ve sel ve taşkınları engellemek amacıyla da dere 1slahı çalışmaları gerekli kurumların denetiminde en kısa zamanda bitirilmelidir. Rekreasyon koridoru başlangıç noktasında ve tarihi-kültürel değerleri koruyan koridor üzerinde otopark alanları tasarlanmalıdır ve turizm koridoruna ise doğal değerlerin korunması amacıyla acil durumlar dışında araç sokulmamalıdır. Otopark alanlarının kurgulandığı noktalarda bisiklet ve elektrikli binek gereçleri (bisiklet, scooter, 
ginger vb.) kiralama alanları kurgulanmalıdır. Ayrıca çalışma alanında yapılacak bitkilendirme tasarımlarında mevcut bitkiler korunmalı, yeni tasarlanacak alanda yörenin doğal türleri kullanılmalıdır ve kompozisyonlarda doğal süs bitkilerinin yanı sıra tıbbi ve aromatik bitkilere de yer verilmelidir.

Rekreasyon koridoru olarak önerilen koridorda; birinci kısım olarak sınıflandırılan kısmın alan imkânları dolayısıyla su kenarının her iki yakası kullanılabilmektedir. Bu durum koridor boyunca 1. kısımda rekreasyonel aktivite çeşitliliğine imkân tanımaktadır. Koridor boyunca yürüyüş ve bisiklet yolları, paten kayma alanları, oturma-dinlenme alanları, ayaküstü yeme-içme alanları, oyun alanları, seyir alanları, oyun alanları, gösteri alanları ve balık tutma alanları tasarlanmalıdır (Şekil 5).

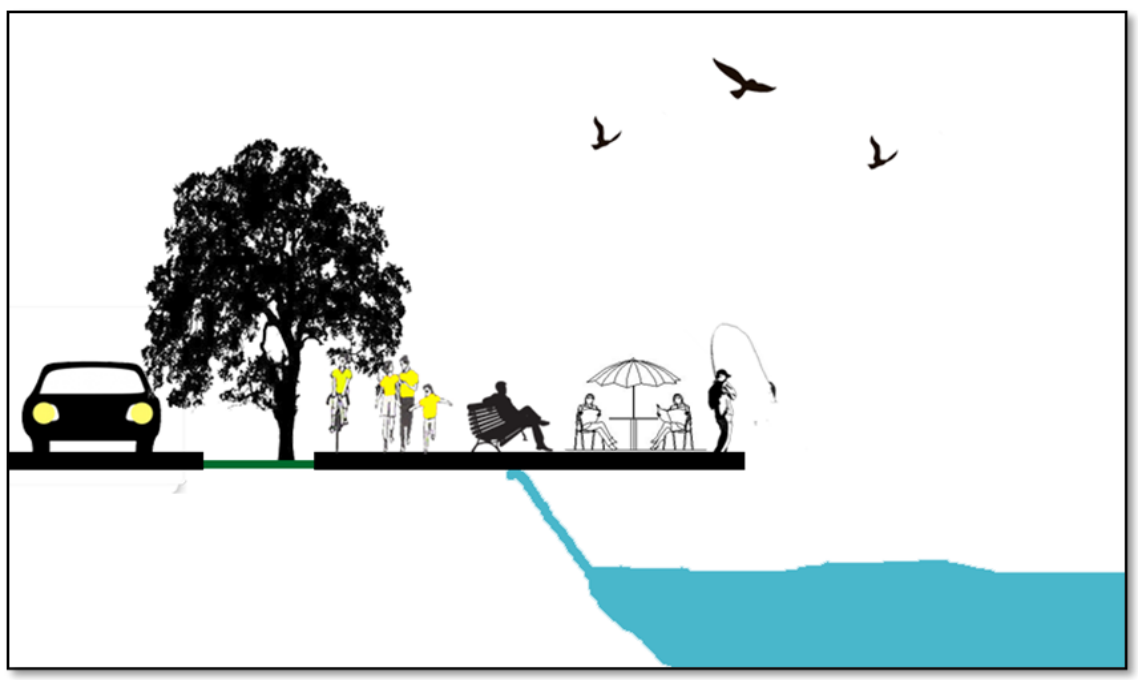

gekil 5. Rekreasyon koridoru (1. kısım) için önerilen bazı aktivitelere ilişkin bir illustrasyon

Rekreasyon koridoru olarak önerilen ikinci kısım ise alan imkânları dolayısıyla bir bağlantı koridoru niteliğinde düşünülmüştür ve bu koridor boyunca yürüyüş ve bisiklet yolları, yer yer oturma-dinlenme alanları ve manzara seyir noktaları oluşturulmalıdır (Şekil 6).

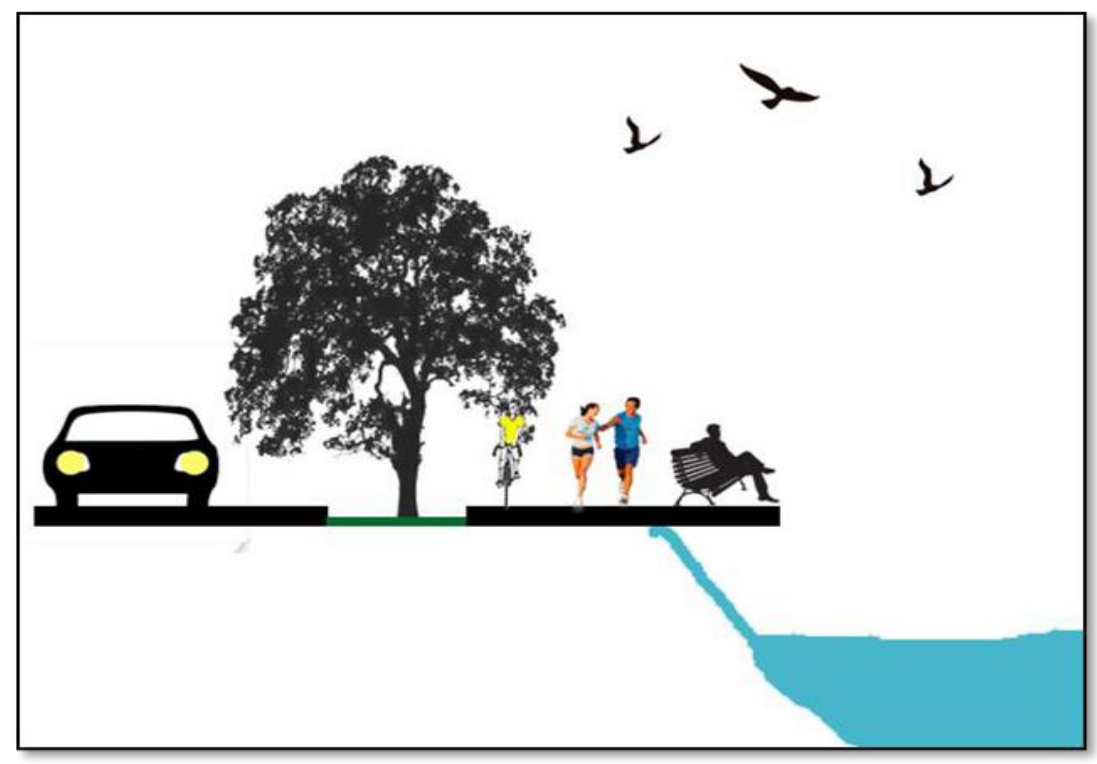

ġekil 6. Rekreasyon koridoru (2. K1sma) için önerilen bazı aktivitelere ilişkin bir illustrasyon 
Önerilen manzara koridoru ve tarihi-kültürel değerlerin korunacağı koridorda mevcutta var olan yeme-içme alanlarının iyileştirileceği ve yöresel yemeklerin sunulmasına teşvik edileceği bir yaklaşım benimsenmelidir. UNESCO tarafından kültürel miras listesine alınan sslık dilinin basit birkaç ifadesinin öğrenilebileceği ve yörenin kültüründe yer alan atmacacılık kültürünün tanıtılabileceği bir alan kurgulanmalıdır. Ayrıca yörenin önemli geçim kaynaklarından birini çay oluşturmaktadır. Gelen ziyaretçilerin çay toplama ritüelini öğrenebilecekleri bir alan planlanmalıdır. Yöredeki topoğrafik yapı dolayısıyla bu alanlara ulaşım ve toplanılan çayların taşınmasında varangela adlı bir sistem kurulmuş̧ur. Bu sistem gerekli tedbirler alınarak su üzerinde kurgulanmalıdır. Böylece kültürünün devamlılığı sağlanarak alana gelen kullanıcıların bu heyecanı yaşamaları sağlanabilir ve ayrıca ekonomik anlamda da yöreye katkı sunulabilir (Şekil 7).

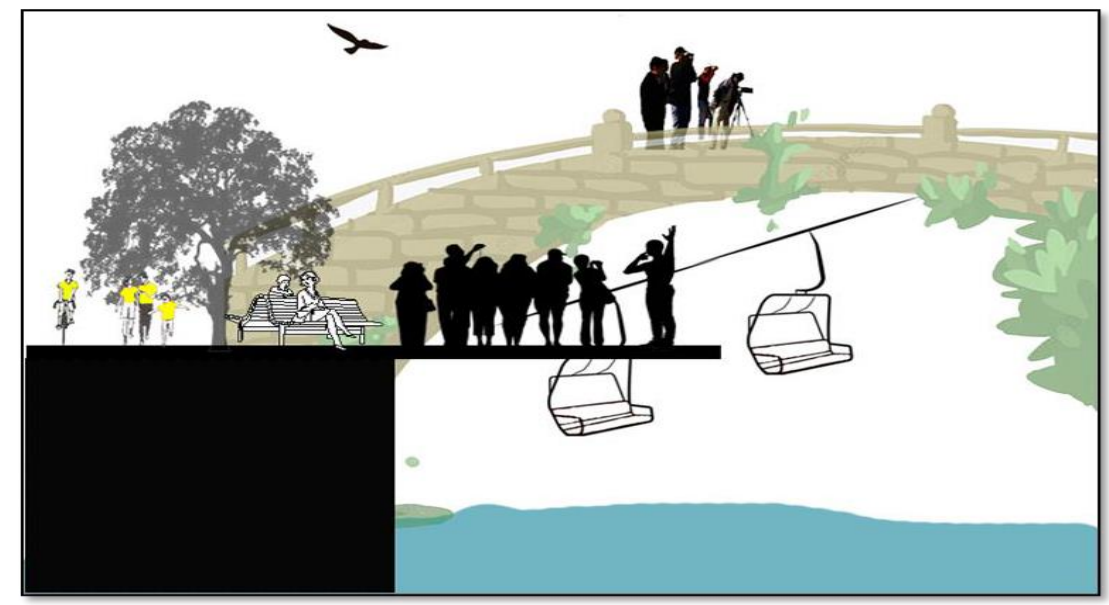

gekil 7. Tarihi-kültürel değerleri koruyan koridor için önerilen bazı aktivitelere ilişkin bir illustrasyon

Manzara ve turizm koridoru olarak önerilen alanda ise yürüyüş ve bisiklet yolları kurgulanmalıdır. Bu koridor kullanıcıların doğayla daha fazla iletişim içerisinde olabilecekleri bir güzergâh olarak düşünülmüştür. Dere kenarında yüzme ve piknik alanları planlanmalıdır. Bu koridorda doğa eğitimi verilecek bir güzergâh belirlenmelidir. İlaveten kamp alanları planlanmalıdır. Oryantiring sporunun yapılabileceği bir alanda kurgulanmalıdır. Gelen kullanıcıların stresten arınmalarını ve kendilerini yenilemelerini sağlayacak su kenarı meditasyon alanları da planlanmalıdır. Koridorda yer alan Mençuna Şelalesi güzergahında trekking rotaları ve manzara seyir noktaları tasarlanmalıdır (Şekil $8)$.

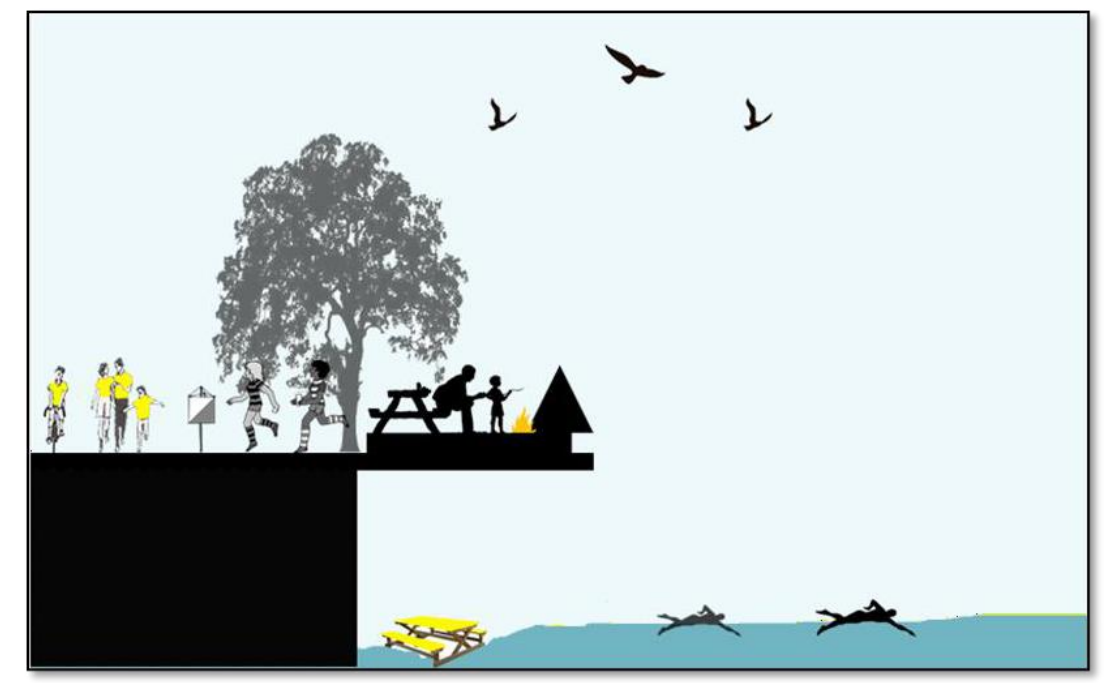

gekil 8. Manzara ve turizm koridoru için önerilen bazı aktivitelere ilişkin bir illustrasyon 
Bu çalışmada yeşilyol olarak planlanması önerilen güzergâhın; mavi bir alanın yeşil bir alanla bütünleştirilerek hem kullanıcılarına (yerel veya turist) hem de kente farkl ekosistem servisleri sunarak mevcut kent ekosistemini desteklemesi hedeflenmiştir. Binyıl Ekosistem Değerlendirmesi (MEA) (2005) ekosistem servislerini; kaynak sağlayan (gıda, dekoratif kaynaklar, biyolojik hammadde, biyokimyasal ve tıbbi ürünler), düzenleyici (hava kalitesini düzenleme, iklim düzenleme su akışı ve erozyon kontrolü, polenleme), destekleyici (fotosentez, besin ve su döngüsünü destekleme) ve kültürel ekosistem servisleri (eğitim, bilgi sistemi, ilham, estetik değerler, sosyal ilişkiler, yer ve mekan hissi, rekreasyon-ekoturizm, sağlık, ekonomi, doğayla bağlantı, duyusal deneyimler) olarak sınıflandırmıştır. Önerilen yeşilyol ile birlikte alanda kurgulanacak doğal bitkiler sayesinde kaynak sağlayan ekosistem servislerinden gıda (meyve), dekoratif kaynaklar (süs bitkileri) ve tıbbı ürünler (tıbbi ve aromatik bitkiler) açısından servisler sağlanacağı, düzenleyici ekosistem servislerinden su kenarında yapılacak müdahaleler neticesinde su akışı kontrolü ve erozyon kontrolü sağlanacağı ve alanda kurgulanacak bitkiler sayesinde alan kuş, böcek ve kelebek gibi canlıların geleceği ve bu sayede polenleme servisine destek sağlanacağ 1 , destekleyici servislerden fotosentez açısından destek sağlanacağı düşünülmektedir. Kültürel ekosistem servisleri açısından ise; kültürel bir değer olan sslak dilinin yaşatılarak ve sürdürülebilirliği sağlanarak manevi ve etik değerler açısından, yöreye özel geleneksel bilgilerin (çay toplama vb.) aktarılmasıyla bilgi sistemi açısından, alanın zaten canlı bir laboratuvar olduğu buna ilaveten alanda kurgulanan etkinlerle de (doğa eğitimi, kamp alanları, oryantiring) eğitim değeri açısından, alanda kurgulanacak mekânlar ve manzara noktaları ile bilimsel ve sanatsal açıdan esin kaynăg olarak ilham açısından, yine manzara noktaları ve mevsimsel değişen bitki örtüsü ile estetik değerler açısından, kurgulanacak olan aktivite alanları sayesinde sosyal ilişkiler açısından, aktivite çeşitlilikleri sayesinde yer ve mekan hissi açısından ve rekreasyonel aktiviteler ve turizm değerlenin korunması açısından da rekreasyon ve eko-turizm parametleri açısından önerilen yeşilyolun kent ekosistemini destekleyeceği düşünülmektedir.

Sonuç olarak, böyle güzergâhların doğru bir şekilde planlanması sonucu doğanın tahribatı en az indirgenerek nitelikli mavi-yeşil alanlar kazandırılacaktır. Bu noktada nitelikli alanların (yeşil, mavi) kazandırılmasında yeşilyollar kilit öneme sahip koridorlardır. Yeşilyollar planlanarak, hem bireylere kendilerini yenileme olasıllğ bulabilecekleri maksimum rekreasyon olanakları sağlanacak hem peyzaj değerleri (doğal ve/veya kültürel) korunacak hem de turizm sayesinde yerel ekonomiye katkı sağlanacaktır.

\section{Etik Standart ile Uyumluluk}

Çıkar ÇatıĢması: Yazar herhangi bir çıkar çatışmasının olmadı̆̆ııı beyan eder.

Etik Kurul Ġzni: Bu çalışma için etik kurul iznine gerek yoktur.

Finansal Destek: Yok.

\section{KAYNAKÇA:}

ACAR, C., SARI, D. 2010. Kentsel yerleşim alanlarındaki bitkilerin peyzajda kullanım tercihleri açısından değerlendirilmesi: Trabzon kenti örneği. Ekoloji, 19(74), 173-180.

AHERN, J. 2013. Urban landscape sustainability and resilience: the promise and challenges of integrating ecology with urban planning and design. Landscape Ecology, 28(6), 1203-1212.

AKPINAR, A. 2016. Factors influencing the use of urban greenways: A case study of Aydın, Turkey. Urban Forestry \& Urban Greening, 16, 123-131.

ANTHONY, W. 2006. Greenways: multiplying and diversifying in the 21st century. Landscape and Urban Planning $76(1-4), 252-290$.

BENEDICT, M.A.; MCMAHON, E. 2006. Green infrastructure: Linking landscapes and communities. Island Press, Washington, DC, USA. 2006, 299 pp.

BENNETT, A.F. 2003. Linkages in the landscape the role of corridors and connectivity in wildlife conservation. The IUCN Forest Conservation Programme, Australia. 
BǴNYIL EKSOSĠSTEM DEĞERLENDĠRMESĠ (MEA), (2005). Ecosystems and Human Well-being: Synthesis, Millennium Ecosystem Assessment. Island Press, Washington, DC.

BUYUKOZKAN, G., MUKUL, E., KONGAR, E. 2020. Health tourism strategy selection via SWOT analysis and integrated hesitant fuzzy linguistic AHP-MABAC approach. Socio-Economic Planning Sciences, 100929 (In Press).

BRYANT, M. M. 2006. Urban landscape conservation and the role of ecological greenways at local and metropolitan scales. Landscape and Urban Planning, 76(1-4), 23-44.

CHEN, Y., GU, W., LIU, T., YUAN, L., ZENG, M. 2017. Increasing the Use of Urban Greenways in Developing Countries: A Case Study on Wutong Greenway in Shenzhen, China. International Journal of Environmental Research and Public Health, 14, 554.

CHON, J., AND SHAFER, C. S. 2009. Aesthetic responses to urban greenway trail environments. Landscape Research, 34(1), 83-104.

CORNING, S. E., MOWATT, R. A., CHARLES CHANCELLOR, H. 2012. Multiuse trails: benefits and concerns of residents and property owners. Journal of Urban Planning and Development, 138(4), 277-285.

DALLAT, M. A. T., SOERJOMATARAM, I., HUNTER, R. F., TULLY, M. A., CAIRNS, K. J., KEE, F. 2014. Urban greenways have the potential to increase physical activity levels costeffectively. European Journal of Public Health, 24(2), 190-195.

EGWA (European Greenways Association), 2002. Declaration of Lille. www.aevv-egwa.org.

ESTOQUE, R.C., MURAYAMA, Y., MYINT, S.W. 2017. Effects of landscape composition and pattern on land surface temperature: an urban heat island study in the megacities of Southeast Asia. Science of the Total Environment, 577, 349-359.

FÁBOS, J.G., RYAN, R.L. 2006. An introduction to greenway planning around the world. Landscape and Urban Planning, 76(1), 1-6.

GOBSTER, P. H. 1995. Perception and use of a metropolitan greenway system for recreation. Landscape and Urban Planning, 33(1), 401-413.

GÖMELĠ, D. 2018. Yerleşkelerde yeşilyol planlaması Karadeniz Teknik Üniversitesi Kanuni Yerleşkesi örneği. Yüksek Lisans Tezi, Karadeniz Teknik Üniversitesi Fen Bilimleri Enstitüsü, Trabzon.

FITZHUGH, E. C., BASSETT, D. R., EVANS, M. F. 2010. Urban trails and physical activity: A natural experiment. American Journal of Preventive Medicine, 39(3), 259-262.

FORMAN, R.T.T. 1995. Land mosaics: The ecology of landscapes and regions. Cambridge University Pres.

JANG, M. KANG, C-D. 2015. Urban greenway and compact land use development: A multilevel assessment in Seoul, South Korea. Landscape and Urban Planning 143 (2015) 160-172.

KEITH, S.J., LARSON, L.R., SHAFER, C.S., HALLO, J.C., FERNANDEZ, M. 2018. Greenway use and preferences in diverse urban communities: Implications for trail design and management. Landscape and Urban Planning, 172, 47-59.

KURT, S.S. 2013. Amasya kenti için yeşilırmak koridorunu içine alan bir kentsel yeşilyol önerisi. Yüksek Lisans Tezi, Karadeniz Teknik Üniversitesi Fen Bilimleri Enstitüsü, Trabzon.

LITTLE, C.E., 1990. Greenways for America. John Hopkins University Press, Baltimore, MD. pp.237. 
LITTLE, C.E., 1995. Greenways for America (Creating the North American Landscape). Johns Hopkins Universtity Press, Baltimore, MD, United States pp. 288.

LIU, X., ZHU, Z., JIN, L., WANG, L., HUANG, C. 2018. Measuring patterns and mechanism of greenway use - A case from Guangzhou, China. Urban Forestry \& Urban Greening 34, 55-63.

LIU, Z., LIN, Y., DE MEULDER, B., WANG, S. 2020. Heterogeneous landscapes of urban greenways in Shenzhen: Traffic impact, corridor width and land use. Urban Forestry \& Urban Greening, 55, 126785.

LOW CHOY, D.C. 2009. A joined-up regional landscape: A Roadmap to connect the parts. Breaking the Barriers: Engineering Solutions to Ecological Problems, Urban Research Program, Griffith University.

NGO, V.D., FRANK, L.D., BIGAZZI, A.Y. 2018. Effects of new urban greenways on transportation energy use and greenhouse gas emissions: a longitudinal study from Vancouver, Canada. Transportation Research Part D: Transport and Environment, 62, 715-725.

NOSS, R.F. 1987. Corridors in real landscape: A reply to simberloff and cox. Conservation Biology, 1(2), 159164.PALARDYA, N.P., BOLEYA, B.B., GAITHER. C.J. 2018. Residents and urban greenways: Modeling support for the Atlanta BeltLine. Landscape and Urban Planning, 169, 250-259.

PANEERCHELVAM, P. T., MARUTHAVEERAN, S., MAULAN, S., SHUKOR, S.F.A. 2020. The use and associated constraints of urban greenway from a socioecological perspective: A systematic review. Urban Forestry \& Urban Greening 47, 126508.

QIN, X., 2012. The comparative study on the Chinese greenway and the American greenway. Landscape Architecture. Beijing Forest University, Beijing pp. 91. (in Chinese).

ROVELLI, R., SENES, G., FUMAGALLI, N., SACCO, J., DE MONTIS, A. 2020. From railways to greenways: a complex index for supporting policymaking and planning. A case study in Piedmont (Italy). Land Use Policy 99, 104835 .

SENES, G., ROVELLI, R., BERTONI, D., ARATA, L., FUMAGALLI, N., TOCCOLINI, A. 2017. Factors influencing greenways use: Definition of a method for estimation in the Italian context. Journal of Transport Geography, 65, 175-187.

SHAFER, C.S., LEE, B.K., TURNER, S. 2000. A tale of three greenway trails: user perceptions related to quality of life. Landscape and Urban Planning, 49 (3-4), 163-178.

SHIFLETT, S.A., LIANG, L.L., CRUM, S.M., FEYISA, G.L., WANG, J., JENERETTE, G.D. 2017. Variation in the urban vegetation, surface temperature, air temperature nexus. Science of the Total Environment, 579, 495-505.

SIMS-GOULD, J., RACE, D.L., VASAYA, N., MCKAYA, H.A. 2019. A new urban greenway in Vancouver, British Columbia: Adolescents' perspectives, experiences and vision for the future. Journal of Transport and Health, 15,100620 .

TAYLOR, P., 2015. What factors make rail trails successful as tourism attractions? Developing a conceptual framework from relevant literature. Journal of Outdoor Recreation and Tourism 12, 89-98.

WEBER, S., BOLEY, B.B., PALARDY, N., GAITHER, C.J. 2017. The impact of urban greenways on residential concerns: Findings from the Atlanta BeltLine Trail. Landscape and Urban Planning 167, 147-156.

YU, Z., YAO, Y., YANG, G., WANG, X., VEJRE, H. 2019. Spatiotemporal patterns and characteristics of remotely sensed regional heat islands during the rapid urbanization (1995-2015) of Southern China. Science of the Total Environment, 674, 242-254. 
YU, Z., YANGA, G., ZUO, S., JØRGENSEN, G., KOGA, M., VEJREA, H. 2020. Critical review on the cooling effect of urban blue-green space: A thresholdsize perspective. Urban Forestry and Urban Greening, 49, 126630.

ZENGĠN, M., DOĞAN, D., ÖZDEDE, S. 2019. Yeşil Yol Planlama: Denizli Pamukkale İlçesi Örneği. Mehmet Akif Ersoy Üniversitesi Fen Bilimleri Enstitüsü Dergisi, 10(2), 166-175. 